\title{
BMJ Open Sexual behaviour patterns and STI risk: results of a cluster analysis among men who have sex with men in Portugal
}

\author{
Karel Blondeel (D) ,1,2 Sonia Dias, ${ }^{3,4}$ Martina Furegato (D) , ${ }^{5,6}$ Armando Seuc, ${ }^{7}$ \\ Ana Gama, ${ }^{3}$ Ricardo Fuertes, ${ }^{8}$ Luís Mendão, ${ }^{8}$ Marleen Temmerman, ${ }^{2,9}$ Igor Toskin ${ }^{1}$
}

To cite: Blondeel K, Dias S, Furegato M, et al. Sexual behaviour patterns and STI risk: results of a cluster analysis among men who have sex with men in Portugal. BMJ Open 2021;11:e033290. doi:10.1136/ bmjopen-2019-033290

- Prepublication history for this paper is available online. To view these files, please visit the journal online (http://dx.doi org/10.1136/bmjopen-2019033290).

$\mathrm{KB}, \mathrm{SD}$ and MF contributed equally.

$\mathrm{KB}, \mathrm{SD}$ and $\mathrm{MF}$ are joint first authors.

Received 29 July 2019 Revised 11 December 2020 Accepted 19 December 2020

\section{A Check for updates}

(c) Author(s) (or their employer(s)) 2021. Re-use permitted under CC BY-NC. No commercial re-use. See rights and permissions. Published by BMJ.

For numbered affiliations see end of article.

\section{Correspondence to} Dr Martina Furegato; martina.furegato2020@gmail. com

\section{ABSTRACT}

Objectives Portugal has the highest HIV incidence rate in Western Europe. The proportion assigned to sexual contact between men recently increased to more than $30 \%$ of all HIV infections. Men who have sex with men (MSM) are vulnerable to the acquisition of other sexually transmitted infections (STIs), increasing the per-contact risk of HIV infection. Building on syndemic theory, the aim of this analysis was to identify patterns of current sexual behaviour in MSM, and explore their relationship with self-reported current, past STI diagnoses and HIV positive serostatus.

Design A cross-sectional behavioural survey was conducted in Portugal among MSM, using a communitybased participatory research approach. Hierarchical cluster analysis was used to identify patterns including behavioural and demographic factors.

Results The analysis resulted in six clusters. Three clusters showed higher rates of current STI diagnosis (ranging from $11.7 \%$ to $17.1 \%$ ), past STI diagnosis (ranging from $25.5 \%$ to $41.5 \%$ ) and HIV positive serostatus (ranging from $13.0 \%$ to $16.7 \%$ ). From the three clusters scoring lower on current and past STI and HIV diagnoses, one was characterised by a high number of sexual partners (62\% had more than 12 partners in the last year), a high proportion $(94.6 \%)$ of frequent visits to gay venues to meet sexual partners and high alcohol use (46.1\%). The other two clusters scored lower on high risk sexual behaviour.

Conclusion Factors other than sexual behaviour appear to reinforce the vulnerability to STIs and HIV of some MSM in this study, suggesting a syndemic of STIs, HIV and other adverse conditions. More research is needed to better understand the drivers of the STI/HIV epidemic in Portuguese MSM, using a concept that goes beyond risk behaviour, to develop effective combination prevention interventions.

\section{INTRODUCTION}

Portugal had the highest rate of new HIV diagnoses in Western Europe in 2013. ${ }^{1}$ Initially, the Portuguese HIV epidemic was predominantly prevalent in people who inject drugs, but since 2003 most of the reported infections are associated with sexual transmission. ${ }^{2}$ In 2013, of all new HIV infections occurring in Portugal, 30.3\% were assigned

\section{Strengths and limitations of this study}

- Hierarchical cluster analysis was used to identify behavioural patterns among men who have sex with men (MSM) participating in a behavioural survey in Portugal.

- The main findings from the cluster analysis are in line with the literature supporting linked epidemics of sexually transmitted infections (STIS) and HIV in Portuguese MSM

- Using a syndemic approach, it was possible to identify that factors not directly linked to sexual behaviour are linked to these epidemics.

- The outcomes of this analysis relate to the study sample population and cannot be generalised to the wider MSM population.

- We acknowledged that the reliance on self-reported STI and HIV outcomes is a weakness that may have caused social desirability bias.

to sexual contact between men. ${ }^{3}$ The estimated percentage of Portuguese men who have sex with men (MSM) living with HIV was $10 \%$ in 2011, manifold the $0.6 \%$ estimate for Portuguese adults aged 15-49. ${ }^{4}$ The median age at HIV diagnosis due to transmission among homosexual men has declined from 35 in 2007 to 32 in 2012, unlike the increasing trend due to transmission among heterosexual persons. ${ }^{5}$

MSM are also vulnerable to the acquisition of other sexually transmitted infections (STIs), some of which increase the percontact risk of HIV infection. The European MSM Internet Survey showed that $14.5 \%$ of MSM across Europe self-reported a history of gonorrhoea diagnoses, $13.4 \%$ of anal/genital warts, $8.6 \%$ of syphilis, $8.1 \%$ of chlamydial infection and $3.6 \%$ of anal/genital herpes. ${ }^{6}$ MSM account for almost $50 \%$ of all syphilis cases reported and $24 \%$ of gonorrhoea diagnoses in Europe. ${ }^{7}$ For Portugal this information is incomplete ${ }^{89}$ and in the Portuguese Global AIDS Response Progress Reports there is no reporting of STI-data among MSM. ${ }^{10}$ 
Under-reporting is suggested to be high in Portugal, and related to the non-detection of syphilis and rectal gonorrhoea due to low rates of STI-testing and anal exams or swabbing. ${ }^{11}$ Currently, in Portugal, there are neither separate HIV/STI-policies for MSM nor specific national STItesting policies or guidelines.

Recently, there have been numerous efforts to promote prevention/diagnosis/linkage of interventions for MSM, mainly organised by the community. CheckpointLX in Lisbon, the first community-based testing centre for MSM founded in April 2011, encourages combined HIV-STI testing for MSM.

The most recent national programme for the prevention and control of HIV/AIDS ${ }^{12}{ }^{13}$ included MSM as a target group. Having as first objective to structure the epidemiological surveillance system for HIV, it encompasses information on other STIs and includes the screening of STIs as a secondary prevention method for HIV infection. ${ }^{14} 15$

STIs and HIV have been researched in conjunction with mental health conditions, substance use, violence and sexual abuse in the framework of the syndemic theory. ${ }^{16}$ These factors may reinforce one another and increase the health burden in at risk populations, such as MSM..$^{20,21}$ The concept of 'afflictions' defining a syndemic ${ }^{16-18}$ can be extended from just diseases to risk factors, and other health-related conditions.

A syndemic of risky sexual behaviours is a group of coexisting factors that describe the sexual behavioural patterns in a specific population.

One way of exploring this syndemic is to identify subgroups of subjects that share a particular pattern with respect to relevant sexual behavioural variables that potentially interact in the syndemic, to this purpose the technique of cluster analysis was used in this study.

The term cluster in this context is not considered in the epidemiological sense of the term, that is, a group that is connected in time and/or place but it was used to identify patterns of current sexual behaviour in Portuguese MSM, and to explore the associations with the self-reported current and past STIs and HIV serostatus.

A better understanding of these relationships can inform the design of combined interventions in MSM to both decrease STI and HIV burden, and improve sexual health. ${ }^{19}$

The aim of this analysis was to identify patterns of current sexual behaviour in MSM, and explore their relationship with self-reported current, past STI diagnoses and HIV positive serostatus.

\section{METHODS}

A cross-sectional behavioural survey was conducted in Portugal among MSM as part of the Project PREVIH-HIV/ AIDS infection in MSM and sex workers: prevalence, determinants, prevention interventions and Access to health (2009-2013). The study used a community-based participatory research approach, engaging a community advisory board $(\mathrm{CAB})$ comprising MSM, representatives of non-governmental and governmental organisations, and academics. The CAB actively participated in the study design, implementation and interpretation of the results. ${ }^{190}$

\section{Sampling, recruitment and data collection}

The study population was reached through a venue-based recruitment strategy. Geographic and network mapping was conducted, based on formative research with the $\mathrm{CAB}$, to identify data collection sites. Recruitment teams of outreach workers and MSM peers systematically approached potential participants at the sites, inviting them for a face-to-face interview. The inclusion criteria were: being at least 18 years and having had sex with a man in the last year. Participants were recruited from gay bars/clubs, cafes, streets in predominantly gay neighbourhoods, local community based organisations and community events. Additionally, the recruited respondents were asked to advertise the study among their social networks and peers.

Anonymity and confidentiality were guaranteed, and informed consent was obtained from all participants.

Data were collected from January to September 2011 using a structured questionnaire applied by trained peers recruited from community organisation partners. The questionnaire included closed-ended questions on sociodemographics, sexual behaviour, availability/ accessibility of STI/HIV services, history of HIV testing, reported HIV status and current/history of other STIs. The questionnaire was developed in collaboration with the community partners and included the indicators of the United Nations General Assembly Special Session on HIV/AIDS. ${ }^{21}$ A more detailed description of the sampling, recruitment and data collection can be found elsewhere. $^{20}$

\section{Patient and public involvement}

A community-based participatory research approach was used, in which a $\mathrm{CAB}$ including representatives of non-governmental and governmental organisations, academics and MSM was formed and actively participated in all phases of the project, as the study design, elaboration of the questionnaire, results interpretation and discussion. Community partners were also involved in the data collection process.

\section{Statistical analysis}

Data were analysed using hierarchical agglomerative cluster analysis, univariate and bivariate statistics, univariable, multivariate and mixed effect logistic regression analyses and statistical packages SPSS V.20.0 and STATA V.13 were used.

Figure 1 shows the cascade of the variables included in each step of the cluster analysis from the inclusion of all the variables and with the exclusion of some factors when the inclusion criteria were not met. 


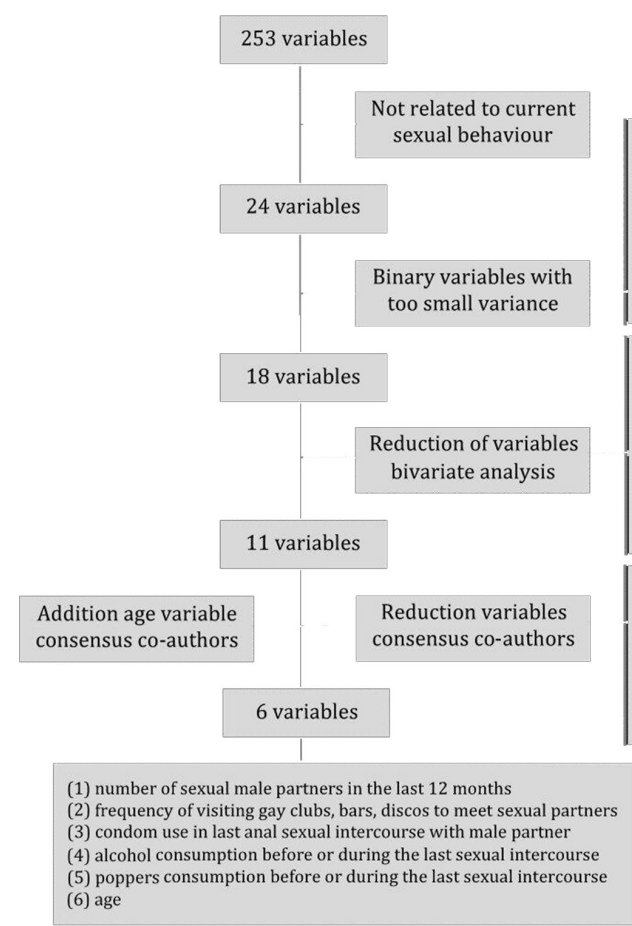

Figure 1 Flow chart of variable selection for the study.

Multiple iterations of a hierarchical cluster analysis were used to identify the optimum number of clusters. The clustering was done based on Euclidean distances. Squared Euclidean distances were used to calculate the distance between any two individuals/subjects in the sample; the squared Euclidean distance is defined as the sum of the squared differences between the values for the (six) variables corresponding to these two individuals/subjects. Distances between identified clusters are obtained with the 'between-groups linkage' method, that is, the average of the distances between any two subjects in the corresponding clusters (syntax available as a online supplemental file 1).

In consultation with key persons from the MSM community in Lisbon, the clusters were not labelled because of possible misperception and stigmatisation and will be referred to with a number.

The frequency of the variables self-reported current STI status ('negative', 'positive', 'don't know'), past STI status ('negative', 'positive', 'don't know') and HIV serostatus ('negative', 'positive', 'don't know') in each of the clusters was examined.

The final list of variables included: (1) number of sexual male partners in the last 12 months (year) expressed as '1', '2-4', '5-12' and '>12'; (2) frequency of visiting gay clubs, bars, discos (venues) to meet male sexual partners ('many times', 'sometimes', 'rarely' and 'doesn't visit'), (3) condom use during the last anal sexual intercourse (AI) with male partner ('yes' and 'no'); (4) alcohol and (5) poppers consumption before or during the last sexual intercourse ('yes' and 'no') and (6) age ('18-20', '21-30', '31-40', '41-50' and '>50').
- amphetamines consumption before or during the last sexual intercourse LSD consumption before or during the last sexual intercourse substance consumption, but doesn' t remember which, before or during the last sexual intercourse last intercourse

- heroine consumption before or during the last sexual intercourse other substance consumption before or during the last sexual intercourse methadone consumption in the last 30 days

- no substance consumption, before or during the last sexual intercourse last intercourse

- condom use in last insertive anal intercourse with male partner

condom use in last receptive anal intercourse with male partner

- number of sexual trans partners in the last 12 months

frequency of visiting gay saunas to meet sexual partners

frequency of visiting cruising spots to meet sexual partners

frequency of visiting internet/gay chat to meet sexual partners

- frequency of visiting gay beaches to meet sexual partners

-

-

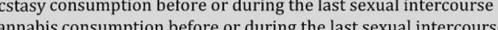

consumption in the last 30days of: Medical drugs (as anxiolytics, hypnotics,

sedatives, antidepressants, psychostimulants)

-condom use in last sexual intercourse with female partner
A sensitivity analysis was performed to test the validity of the variables identified through the clustering. The variables identified were included as covariates in multivariable logistic regression models using the variable self-reported current STI status ('negative' vs 'positive'), previous STI status ('negative' vs 'positive') and HIV serostatus ('negative' vs 'positive') as outcomes. The results of the regression models for current and previous STIs and HIV status can be found as online supplemental files 1-4. In addition, in regression analysis, the multilevel structure induces correlation among observations within a cluster and to test the validity of the six variables identified, each of them was used independently as a random effect in mixed-effect logistic regression models.

The final list of variables identified was considered as potential factors of a pattern of sexual behaviour in MSM populations.

\section{RESULTS}

A total of 1046 MSM participated in this study. The refusal rate was 23.2\% (1362 were approached). No differences were found between refusals and participants regarding age and education. Overall, $5.5 \%$ self-reported a current STI, $20.5 \%$ a previous STI and $9.1 \%$ HIV positive serostatus. The median and mean numbers of male sexual partners in the past year were 4 and 14.8, respectively. Condom use was reported by $76.2 \%$ of participants during their last AI, either receptive or insertive; alcohol and poppers used before or during the last AI was reported by $25.3 \%$ and $7.8 \%$, respectively. 
Table 1 Sociodemographic and behavioural characteristics of the clusters

\begin{tabular}{|c|c|c|c|c|c|c|c|}
\hline & \multicolumn{6}{|c|}{ Clusters } & \multirow[b]{2}{*}{ Overal } \\
\hline & 1 & 2 & 3 & 4 & 5 & 6 & \\
\hline Frequency & 46 & 187 & 206 & 303 & 106 & 66 & 1046 \\
\hline Age-range & $40-73$ & $18-47$ & $18-49$ & $18-48$ & $18-50$ & $41-78$ & $18-78$ \\
\hline $\begin{array}{l}\text { Male sexual partners } \\
\text { in the last year, } \%\end{array}$ & 58 & 81 & 62 & 85 & 59 & 79 & \\
\hline $\begin{array}{l}\text { ( } \% \text { of }>12 \text { parnters } \\
\text { or } \%<5 \text { partners) }\end{array}$ & $>12$ & $<5$ & $>12$ & $<5$ & $>12$ & $<5$ & \\
\hline $\begin{array}{l}\text { Condom use at last } \\
\mathrm{Al}(\%)\end{array}$ & 82.6 & 69.0 & 93.7 & 66.30 & 84.0 & 62.1 & 76.2 \\
\hline $\begin{array}{l}\text { Use of alcohol before } \\
\text { or during last sexual } \\
\text { intercourse (\%) }\end{array}$ & 30.4 & 28.9 & 46.1 & 18.2 & 15.1 & 15.2 & 25.3 \\
\hline $\begin{array}{l}\text { Use of poppers } \\
\text { before or during last } \\
\text { sexual intercourse } \\
(\%)\end{array}$ & 13.0 & 4.8 & 13.1 & 3.6 & 18.9 & 3.0 & 7.8 \\
\hline $\begin{array}{l}\text { Sexual intercourse } \\
\text { with a transgender } \\
\text { partner in the last } 12 \\
\text { months }\end{array}$ & 7.1 & 4.2 & 6.6 & 2.1 & 1.0 & 10.5 & 4.2 \\
\hline $\begin{array}{l}\text { Sexual intercourse } \\
\text { with a woman in the } \\
\text { last } 12 \text { months }\end{array}$ & 12.5 & 19.4 & 8.0 & 10.5 & 13.4 & 28.1 & 13.2 \\
\hline $\begin{array}{l}\text { Sexual intercourse } \\
\text { with a sex worker in } \\
\text { the last } 12 \text { months }\end{array}$ & 11.6 & 3.9 & 3.5 & 3.0 & 4.0 & 17.2 & 4.8 \\
\hline
\end{tabular}

Al, anal intercourse.

The cluster analysis resulted in a 7-cluster solution, but one cluster was discarded as it was too small to be epidemiologically relevant $(\mathrm{n}=12)$.

The characteristics of the clusters identified are presented in table 1 .
Cluster 1: This is the smallest cluster $(n=46)$ with MSM who were almost all older than 40 years old. They reported relatively more male sexual partners compared with the other clusters $(58.7 \%$ reported 13 or more partners in the last year), $71.7 \%$ sometimes or often visited gay venues. 
Eighty-two per cent reported condom use during the last AI, however, almost half (48.4\%) reported unprotected AI in the last year with a partner whose HIV serostatus was unknown and $53.5 \%$ took part in group sex in the last year.

Cluster 2: In this cluster $(\mathrm{n}=187)$ MSM in their twenties were highly represented. Compared with the other clusters, they reported relatively fewer male sexual partners (81.3\% had less than five in the last year), $69 \%$ reported condom use during the last $\mathrm{AI}$ and $90.4 \%$ sometimes or often visited gay venues.

The use of alcohol and poppers during or before the last sexual intercourse was reported by the $28.9 \%$ and $4.8 \%$ of respondents, respectively.

Cluster 3: This cluster $(\mathrm{n}=206)$ included almost exclusively MSM between 20 and 40 . They all reported relatively more male partners $(61.7 \%$ had 13 or more partners in the last year). This cluster showed the highest proportion of condom use during the last AI (93.7\%) and of visiting sometimes or often gay venues $(94.6 \%)$.

The use of alcohol and poppers before or during the last sexual intercourse was reported by $46.1 \%$ and $13.1 \%$, respectively.

Cluster 4; This cluster was the largest $(n=303)$ and assembled the highest percentage of people between 18 and 20. They reported relatively few male sexual partners (85.1\% had four or less partners in the last year), $66 \%$ reported condom use at the last $\mathrm{AI}$ and just $4 \%$ sometimes or often visited gay venues.

Sixty-six per cent reported the use of condom during the last AI while $18.2 \%$ reported the use of alcohol and $3.6 \%$ reported the use of poppers during or before the last sexual intercourse.

Cluster 5; Mostly MSM in their thirties populated this cluster $(n=106)$. Compared with the other clusters, they reported relatively more male sexual partners, $(58.5 \%$ had 13 or more in the last year), $84 \%$ reported condom use during the last AI and only a small proportion visited sometimes or often gay venues.

Eighty-four per cent reported the use of condom during the last AI while $15.1 \%$ used alcohol before or during the last sexual intercourse and $18.9 \%$ used poppers.

Cluster 6; This cluster $(\mathrm{n}=66)$ consisted of exclusively MSM older than 40 years. Over three-quarter reported four or less partners in the last year and only $1.5 \%$ reported to have attended gay venues. Of all clusters, they reported the lowest condom use during the last AI (62.1\%) and only marginally use alcohol $(15.2 \%)$ or poppers $(3.0 \%)$ before or during the last sexual intercourse.

Of all the clusters, this group reported the most frequently sex with a transgender partner, with a woman and with a sex worker $(10.5 \%, 28.1 \%$ and $17.2 \%$, respectively).

From the 120 participants excluded from the cluster analysis, 1 failed to give his age, 63 did not answer how many partners they had in the last year, 26 failed to mark the frequency of their visits to gay venues and 62 did not answer whether they used a condom at last AI. Compared

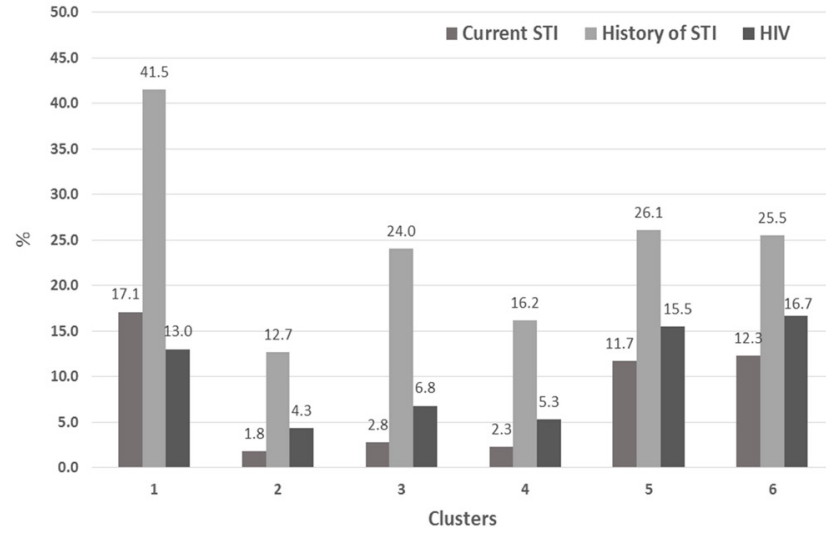

Figure 2 Percentages of reported current STI diagnosis, history of STI diagnosis and HIV positive sero-status in the six clusters.

with the whole study population, the group of excluded participants was older, had less partners, frequented gay venues less frequently, more condom and less alcohol and poppers use.

Figure 2 shows the frequency of reported current STIs, past STIs and HIV serostatus within the six clusters. Cluster 1 had the highest rate of self-reported current STIs $(17.1 \%)$, followed by cluster $6(12.3 \%)$ and cluster 5 $(11.7 \%)$. The other clusters had lower STI rates, ranging from $1.8 \%$ to $2.8 \%$. The proportion of participants that did not know their current STI-status varied from $4.9 \%$ in cluster $1 \%$ to $17.0 \%$ in cluster 5 .

Among the excluded participants that answered the question on reported current STI, the prevalence was $10.7 \%$ which is more than double the prevalence of the participants included in the analysis.

Cluster 1 reported the highest proportion of selfreported STI history $(41.5 \%)$ followed by cluster 5 $(26.1 \%)$, cluster $6(25.5 \%)$ and cluster $3(24.0 \%)$.

The highest prevalence of self-reported HIV was also found within the three clusters (from $13.0 \%$ to $16.7 \%$ ) with the highest self-reported current and past STIs. Among the excluded participants, almost one in five reported being HIV-positive, a higher rate than any of the clusters.

From the sensitivity analysis, the mixed-effect models performed generally better than the multivariable logistic regression. The results presented here are from the mixedeffect models after adjusting for the other confounders (in the fixed part of the model). For the model on selfreported current STIs (online supplemental file 2), age group and number of male sexual partners in the last year were statistically significant random effects. For the model on the self-reported previous STI (online supplemental file 3), age group, number of male sexual partners in the last year and condom use during the last AI were statistically significant random effects. For the model on the self-reported positive HIV sero-status (online supplemental file 4), age group, number of male sexual partners in the last year and frequent visits to gay venues were significant random effects. 
The mixed-effect models, confirmed the role of age, number of sexual partners, condom use and frequent visits to gay venues as factors that could be used to detect possible clusters in this MSM population, related to current or past STI diagnosis or HIV sero-status.

\section{DISCUSSION}

The cluster analysis identified six clusters with diverse patterns of sexual behaviours, related to different STI and HIV vulnerability.

\section{High risk pattern - high STI/HIV-vulnerability}

Cluster 1 seems to be characterised by this pattern: it presents the highest STI rates and high number of partners and a high proportion of at risk sexual behaviours such as group sex and unprotected sex with a partner whose HIV serostatus was unknown. This is in line with previous studies demonstrating that relationships in which condomless sex happens, are multiple, overlapping and sequential, resulting in a high-risk level for STIs and HIV. \{Singer, 2006 \#119;Ferrer, 2015 \#212\}

\section{Seemingly low risk pattern: high STI/HIV-vulnerability}

Cluster 6 was the oldest cluster, and although except for UAI, it scored low on the other sexual risk variables, but it had the second highest STI-prevalence and the highest HIV prevalence. They reported having sexual intercourses with transgender partners, women and sex workers.

This suggests that cluster 6 contained a group of older MSM that might not identify as gay and might face a lot of barriers to access reliable information about the risks of their sexual behaviours. A previous study from Portugal showed that in this sample of MSM, low self-risk perception was the major motive of never having been tested for HIV. $^{22}$

\section{Similar patterns: different STI/HIV-vulnerability}

Both clusters 5 and 3 represented a sexually active pattern in MSM of the same age range. A quarter of MSM in both clusters reported past STI diagnoses but MSM in cluster 5 had a higher proportion of current STI diagnoses, suggesting higher recurrence of STIs, and much higher self-reported HIV prevalence. However, about the same proportion in each cluster reported unprotected AI in the last year with a partner whose HIV sero-status was unknown. Contrary to cluster 3, MSM in cluster 5 almost never visited gay venues and did not drink alcohol at last AI. It has been demonstrated that the frequency of unprotected intercourse does not solely explain risk exposure, but having unprotected intercourse within certain highrisk sexual networks does expose MSM to a heightened risk. $^{23}$

The majority of MSM in these clusters was currently not affected by HIV or other STIs and although they would be categorised as high risk to be infected with STIs and HIV, there are protective factors, among others shamelessness, social support and self-monitoring, that might play an important role in HIV/STI prevention interventions but have not been researched enough.

\section{Strengths and limitations}

Data on HIV and STI prevalence were self-reported and interviews were not self-administered but done by community-based researchers who were trained to apply the questionnaire. This might have provoked memory and social desirability bias. There might be a bias as to why certain questions were not answered, as is suggested by the high self-reported HIV prevalence in the 'missing' cluster. Due to the intimate and sensitive nature of the study questionnaire and the stigma associated with risky sexual behaviour and HIV/STI positive sero-status, underreporting in this study was to be expected.

The strength of a cluster analysis is that it can intercept groups of homogeneous units in the population, in terms of a group of relevant variables. However, the results and interpretation of any cluster analysis depend on several researcher's choices and assumptions, such as that actual groups exist, the choice of the variables on which the elements in the groups should be similar, the distance measure, the clustering procedure and the number of clusters. $^{2425}$

The presented clusters describe the study sample population, obtained via venue-based recruitment, and therefore, cannot be extrapolated to the whole MSM population.

\section{CONCLUSIONS}

Though results of our analysis reconfirm that the number of partners and condom use are important factors in HIV and STI transmission, they also suggest other factors such as sexual networks and risk perception are at play. Although it is difficult to prove that the group of afflictions identified as one of the common patterns in this MSM population is a syndemic, its potential is significant. The findings are also in line with previous studies that demonstrated the association between HIV infection and higher incidence and prevalence rates of other STIs, supporting linked epidemics of STIs and HIV in Portuguese MSM. ${ }^{26-28}$ Interventions for MSM should combine HIV- testing and STI- testing, and for some of the clusters identified in our analysis, should be comprehensive, including rectal and pharyngeal swabbing to screen for asymptomatic gonorrhoea and chlamydia, especially considering the current challenges with antimicrobial resistance. $^{29}$

It should be mentioned that, the information on the natural history of these asymptomatic infections is scarce, and the public health benefit and the risks associated with the wide roll-out of this screening strategy remain unclear.

Finally, the authors recommend future research and interventions to have a syndemic orientation to minimise excess burden of disease in MSM. Capturing concepts of autonomy, well-being, sexual satisfaction, intimacy and social values in relation to sexuality, might unfold a 
different set of risk and protective factors for a healthy sexual life.

\section{Author affiliations}

${ }^{1}$ UNDP-UNFPA-UNICEF-WHO-World Bank Special Programme of Research, Development and Research Training in Human Reproduction (HRP), Department of Sexual and Reproductive Health and Research, WHO, Geneve, Switzerland ${ }^{2}$ Faculty of Medicine and Health Sciences, Ghent University, Gent, Belgium ${ }^{3}$ Global Health and Tropical Medicine, Instituto de Higiene e Medicina Tropical, Universidade Nova de Lisboa, Lisboa, Portugal

${ }^{4}$ National School of Public Health, Universidade Nova de Lisboa, Lisboa, Portugal ${ }^{5}$ Applied Diagnostic Research and Evaluation Unit (ADREU), University of London, St George's Molecular and Clinical Sciences Research Institute, London, UK ${ }^{6}$ Blood Safety, Hepatitis, Sexually Transmitted Infections (STI) and HIV Service, National Infection Service, Public Health England, London, UK

${ }^{7}$ Instituto Nacional de Higiene Epidemiología y Microbiología, Habana, Cuba

${ }^{8}$ Grupo de Ativistas em Tratamentos, Lisbon, Portugal

${ }^{9}$ Medical College, Aga Khan University, Nairobi, Kenya

Correction notice This article has been corrected since it was first published. Affiliation for Marleen Temmerman has been corrected and the provenance and peer review statement has been included.

Acknowledgements The project team is thankful to GHTM-UID/Multi/04413/2013. The authors would like to thank the project team, namely, Daniel Simões, Gabriela Cohen, Inês Rego, Ricardo Fernandes, Ricardo Rosa and Sara Trindade. The authors are also very grateful to all the community partners of the project. The authors thank all the participants of this study.

Contributors SD, AG, RF and LM were involved in the design and conducting of the survey. AS, IT and KB chose the main directions for data analysis and participated in the interpretation of results. AS, MF and KB performed the statistical analyses. $\mathrm{KB}, \mathrm{IT}, \mathrm{MF}, \mathrm{SD}, \mathrm{AS}, \mathrm{MT}$, AG collaborated in the writing of the manuscript. RF and LM complemented the manuscript with contextual data. $K B, S D, M F, A S, A G, R F, L M$, MT and IT revised the manuscript before submission. All authors approved the final manuscript submitted.

Funding The authors have not declared a specific grant for this research from any funding agency in the public, commercial or not-for-profit sectors.

Disclaimer Authors IT and KB alone are responsible for the views expressed in this publication and do not necessarily represent the decisions or the policies of the UNDP-UNFPA-UNICEF-WHO-World Bank Special Programme of Research, Development and Research Training in Human Reproduction (HRP) or the World Health Organization (WHO)

Competing interests None declared.

Patient consent for publication Not required.

Ethics approval This article does not contain any studies with animals performed by any of the authors. All procedures performed involving human participants in this study were in accordance with the ethical standards of the institutional and/ or national research committee and with the 1964 Declaration of Helsinki and its later amendments or comparable ethical standards. The study was approved by the Ethics Committee for Health of the North Regional Health Administration. The ethics committee approval number is No.18.09CES.

Provenance and peer review Not commissioned; externally peer reviewed.

Data availability statement Data are available on reasonable request. The data that support the findings of this study are available on request from the corresponding author MF.

Supplemental material This content has been supplied by the author(s). It has not been vetted by BMJ Publishing Group Limited (BMJ) and may not have been peer-reviewed. Any opinions or recommendations discussed are solely those of the author(s) and are not endorsed by BMJ. BMJ disclaims all liability and responsibility arising from any reliance placed on the content. Where the content includes any translated material, BMJ does not warrant the accuracy and reliability of the translations (including but not limited to local regulations, clinical guidelines, terminology, drug names and drug dosages), and is not responsible for any error and/or omissions arising from translation and adaptation or otherwise.

Open access This is an open access article distributed in accordance with the Creative Commons Attribution Non Commercial (CC BY-NC 4.0) license, which permits others to distribute, remix, adapt, build upon this work non-commercially, and license their derivative works on different terms, provided the original work is properly cited, appropriate credit is given, any changes made indicated, and the use is non-commercial. See: http://creativecommons.org/licenses/by-nc/4.0/.

ORCID iDs

Karel Blondeel http://orcid.org/0000-0001-6900-9124

Martina Furegato http://orcid.org/0000-0003-2168-8396

\section{REFERENCES}

1 European Centre for Disease Prevention and Control/ WHO Regional Office for Europe. HIVIAIDS surveillance in Europe 2013. Stockholm: European Centre for Disease Prevention and Control, 2014.

2 Cortes Martins H, Paixao M. Settings for identifying recent HIV infections: the Portuguese experience. Euro Surveill 2008;13.

3 Departamento de Doenças Infecciosas. Unidade de Referência E Vigilância Epidemiológica. Núcleo de Vigilância Laboratorial de Doenças Infecciosas; colab. Programa Nacional para a Infeção VIH/ SIDA. Infeção VIHISIDA: a situação em Portugal a 31 de dezembro de 2013. Lisboa: INSA, 2014.

4 Joint United Nations Programme on HIV/AIDS (UNAIDS). Global report: UNAIDS report on the global AIDS epidemic. Geneva, 2012.

5 Ministério da Saúde and INSA. Infeção VIH/SIDA: a situação em Portugal a 31 de dezembro de 2012. Lisboa: INSA, 2013.

6 The EMIS Network. EMIS 2010: the European Men-Who-Have-SexWith-Men Internet survey. Findings from 38 countries. Stockholm: ECDC, 2013.

7 European Centre for Disease Prevention and Control. Sti and HIV prevention in men who have sex with men in Europe. Stockholm: ECDC, 2013.

8 European Centre for Disease Prevention and Control. Sexually transmitted infections in Europe, 1990-2009. Stockholm: ECDC, 2011.

9 European Centre for Disease Prevention and Control. Sexually transmitted infections in Europe 2012. Stockholm: ECDC, 2014.

10 UNAIDS. Global AIDS response progress reporting. Portugal, 2014.

11 Schmidt AJ, Hickson F, Weatherburn P, et al. Comparison of the performance of STI screening services for gay and bisexual men across 40 European cities: results from the European MSM Internet survey. Sex Transm Infect 2013;89:575-82.

12 Ministério da Saúde. Programa nacional de prevenção E controlo de infecção VIH E SidA 2012-2016. Lisboa: Ministério da Saúde.

13 Ministério da Saúde. Programa nacional para a infecção VIH/SIDA: Orientações programáticas. Lisboa: Ministério da Saúde.

14 Dias S. The role of men who pay for sex in STI transmission: current knowledge and future directions. The contribution of the third UK national survey of sexual attitudes and lifestyles (Natsal-3). Sex Transm Infect 2015;91:78-9.

15 Dias S, Gama A, Pingarilho M, et al. Health services use and HIV prevalence among migrant and national female sex workers in Portugal: are we providing the services needed? AIDS Behav 2017;21:2316-21.

16 Singer M. The politics of AIDS. Soc Sci Med 1994;38:1321-4.

17 Singer M, Bulled N, Ostrach B, et al. Syndemics and the biosocial conception of health. Lancet 2017;389:941-50.

18 Singer MC, Erickson PI, Badiane L, et al. Syndemics, sex and the city: understanding sexually transmitted diseases in social and cultural context. Soc Sci Med 2006;63:2010-21.

19 Dias S, Gama A, Fuertes R, et al. Utilização de serviços de saúde relacionados CoM a infecção VIH POR parte de homens gays: Acesso a informação, prevenção E teste. PSICOLOGIA 2012;26:109-28.

20 Gama A, Abecasis A, Pingarilho M, et al. Cruising venues as a context for HIV risky behavior among men who have sex with men. Arch Sex Behav 2017;46:1061-8.

21 Joint United nations programme on HIV/AIDS (UNAIDS). monitoring the Declaration of commitment on HIV/AIDS: guidelines on construction of core indicators - 2010 reporting. Geneva 2012.

22 Meireles $\mathrm{P}$, Lucas R, Martins A, et al. The lisbon cohort of men who have sex with men. BMJ Open 2015;5:e007220.

23 Amirkhanian YA. Social networks, sexual networks and HIV risk in men who have sex with men. Curr HIVIAIDS Rep 2014;11:81-92.

24 Green PE, Carmone FJ, Smith SM. Dimension reducing methods and cluster analysis. In: Multidimensional scaling. 1989. revision, ed. Boston: Addison Wesley, 2011.

25 Mooi E, Sarstedt M. A concise guide to market research: The process, data and methods using IBM SPSS statistics. Berlin Heidelberg: Springer-Verlag, 2011. 
26 Ling DI, Janjua NZ, Wong S, et al. Sexually transmitted infection trends among gay or bisexual men from a clinic-based sentinel surveillance system in British Columbia, Canada. Sex Transm Dis 2015;42:153-9.

27 Pisani E, Girault P, Gultom M, et al. Hiv, syphilis infection, and sexual practices among transgenders, male sex workers, and other men who have sex with men in Jakarta, Indonesia. Sex Transm Infect 2004;80:536-40.
28 Pérez-Hernández I, Palacios R, González-Doménech C, et al. Should screening for Chlamydia trachomatis and Neisseria gonorrhoeae in HIV-men who have sex with men be recommended? J Int AIDS Soc 2014;17:19661.

29 Marcus U, Ort J, Grenz M, et al. Risk factors for HIV and STI diagnosis in a community-based HIV/STI testing and counselling site for men having sex with men (MSM) in a large German City in 20112012. BMC Infect Dis $2015 ; 15: 14$. 